\title{
Effect of Water on the Stability of Quaternary Ammonium Groups for Anion Exchange Membrane Fuel Cell Applications
}

\author{
Dario R. Dekel, ${ }^{*}{ }^{\dagger},+$ Michal Amar, ${ }^{\dagger}$ Sapir Willdorf, ${ }^{\dagger}$ Monica Kosa, ${ }^{\S}$ Shubhendu Dhara, ${ }^{\S}$ \\ and Charles E. Diesendruck*,\$(1) \\ ${ }^{\dagger}$ The Wolfson Department of Chemical Engineering, Technion-Israel Institute of Technology, Haifa 3200003, Israel \\ ${ }^{\ddagger}$ The Nancy \& Stephan Grand Technion Energy Program (GTEP), Technion-Israel Institute of Technology, Haifa 3200003, Israel \\ ${ }^{\S}$ Schulich Faculty of Chemistry, Technion-Israel Institute of Technology, Haifa 3200003, Israel
}

Supporting Information

\begin{abstract}
Here we present a novel methodology to measure the alkaline stability of anion conducting polymers to be used as anion exchange membranes and anion exchange ionomers for fuel cells. The new ex situ technique simulates the environment of an anion exchange membrane fuel cell (AEMFC) during operation, where nucleophilic and basic $\mathrm{OH}^{-}$species in the absence, or with a scarce amount of water, attack the functional groups of the ionic polymer. Using this technique, we clearly show the critical effect of water molecules on the alkaline stability of quaternary ammonium (QA) cations commonly used as functional groups in AEMFCs.

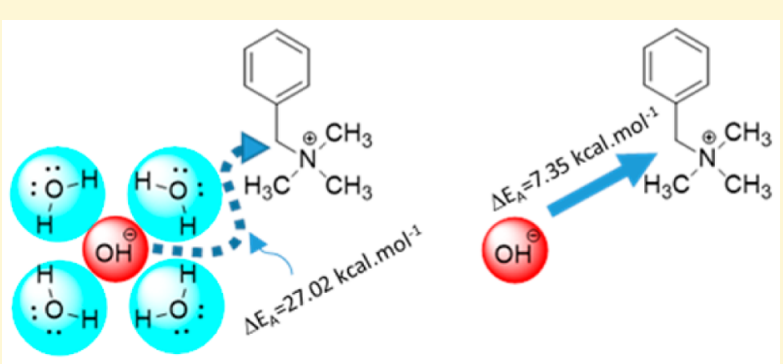
The results show that as the water content is reduced, the QA cations are more rapidly degraded in the presence of $\mathrm{OH}^{-}$at room temperature. With an increasing number of water molecules solvating the hydroxide, its nucleophilicity and basicity are hindered, and the QA degradation is significantly slowed. These results indicate that the currently used aqueous alkali ex situ tests to measure anion exchange membrane (AEM) stability may lead to false positive stability results where anion conducting polymers may appear more alkali stable than they really are.
\end{abstract}

\section{INTRODUCTION}

There is an increasing worldwide interest in anion exchange membrane fuel cells (AEMFCs) due to the potential of this technology to use low cost electrocatalysts, promising a considerable cost reduction for a new generation of fuel cell devices. ${ }^{1}$ However, the stability of anion conducting polymers for durable anion exchange membranes (AEMs) and anion exchange ionomers (AEIs) is still a great concern. ${ }^{2-9}$ In the high $\mathrm{pH}$ environment of the AEMFCs, the molecular structure of the AEM/AEI itself breaks down due to the strong reactivity of the hydroxide anions with the quaternary ammonium (QA) cation functional groups. ${ }^{10,11}$ This decomposition leads to a detrimental reduction of the AEM (or AEI) ion exchange capacity (IEC), ${ }^{12-16}$ reducing its anion conductivity and therefore its capability to serve as an ionomeric material in the fuel cell device.

Numerous studies have been devoted to try to measure the stability of anion conducting polymers in the alkaline environment of the AEMFC. ${ }^{10,17}$ The main problem evaluating the ex situ alkali stabilities of various AEMs with different chemistries is the broad range of different methodologies used throughout the literature. A common approach is to evaluate the reduction of IEC and/or the ionic conductivity of the polymeric AEMs or to study the chemical decomposition of small molecule models with increasing immersion times in strong aqueous alkali solutions, such as $1-6 \mathrm{M} \mathrm{KOH}$ at elevated temperatures. ${ }^{18-21}$ Nevertheless, this ex situ methodology does not precisely simulate the severe environment of the anion conducting polymer in an operating AEMFC, where water is a reactant in the electrochemical oxygen reduction reaction. $^{22,23}$ Water concentration at the cathode side is significantly lower than the water present in all currently used ex situ techniques. In an operating AEMFC, as current densities increase, the water concentration decreases more and more, and at a certain current density threshold the water concentration at the cathode side is practically reduced to zero. As the aqueous alkali ex situ stability measurements commonly used in the literature do contain water molecules, this technique does not measure the true in situ alkaline stability of the anion conducting polymer during AEMFC operation, as the hydroxide is solvated by water and its reactivity significantly changes with the solvation. Even in the case of very high alkaline concentrations reported in the literature (6-10 M $\mathrm{KOH}),{ }^{24,25}$ the number of water molecules present is sufficient to provide false positive stability results, and the anion conducting polymer may appear more alkali stable than it really is.

Received: March 8, 2017

Revised: April 30, 2017

Published: May 2, 2017 
Clearly, as more QAs and alkali anion conducting polymers for fuel cells are developed, ${ }^{26-31}$ a reliable and representative $e x$ situ alkaline stability test protocol must be developed to better simulate the severe environment of AEMFCs, and mimic the reactivity of the hydroxide on the cationic functional groups of AEMs in the absence of water molecules. There are important factors that affect the stability of AEMs when compared to stability of simple QAs, such as steric hindrance and slow diffusion of reactants in the solid state. Still, the effect of water on stability observed during the testing of QAs should be retained when these groups are incorporated into AEMs. In this work we present for the first time an ex situ alkaline stability methodology to measure the alkaline stability of QAs relevant to anion conducting polymers in a water-free environment, which better simulates the real operating conditions of AEMFC. DFT simulations of the nucleophilic attack of hydroxide at the QAs with different amounts of solvating water molecules further support the experimental outcome on the decisive role of $\mathrm{OH}^{-}$solvating water molecules.

\section{EXPERIMENTAL SECTION}

Preparation of Water-Free Hydroxide Solution. 18-Crown-6 ( 8.136 g, 30.8 mmol, 1.5 equiv; Sigma-Aldrich, 3000 ppm water by Karl Fischer) was inserted into an oven-dried three necked roundbottom flask under argon. The solid was then heated under stirring up to $60{ }^{\circ} \mathrm{C}$, where full melting of the crown ether is observed and a liquid is obtained. Potassium metal ( $0.8 \mathrm{~g}, 20.5 \mathrm{mmol}, 1.0$ equiv; $98 \%$, Merck) was then added to the flask, which slowly changed its color to a dark blue. After full dissolution of the potassium metal, milli- $\mathrm{Q}$ water (ca. $344 \mu \mathrm{L}$ ) was slowly added to the solution to titrate the potassium, producing dry potassium hydroxide. When the color of the reaction mixture changed to brown/orange, the flask was cooled down to room temperature, sealed, and transferred to a glovebox for use in NMR kinetic experiments.

Kinetic Studies. NMR tubes (Wilmad-LabGlass) with a septum were used for these studies, using dry DMSO- $d_{6}(99.96 \%$, Cambridge Isotope Laboratories, $63 \mathrm{ppm}$ water by Karl Fischer). Two QA salts were investigated, trimethylbenzyl ammonium bromide (TMBA, Sigma-Aldrich) and triethylbenzyl ammonium chloride (TEBA, Sigma-Aldrich). For each experiment, two solutions were prepared inside the glovebox, under dry nitrogen atmosphere: (1) A $0.5 \mathrm{mmol}$ portion of the previously prepared crown ether $/ \mathrm{KOH}$ mixture was dissolved in $400 \mu \mathrm{L}$ of DMSO- $d_{6}$. (2) The QA salt $(0.035 \mathrm{mmol})$ was dissolved in $100 \mu \mathrm{L}$ of DMSO- $d_{6}$, and $1.5 \mu \mathrm{L}$ of mesitylene (SigmaAldrich) was added to serve as internal standard. The NMR tube was filled with the $400 \mu \mathrm{L}$ of the first (crown ether/KOH) solution, closed with the septum, and sealed. The second solution was transferred to a $1 \mathrm{~mL}$ disposable syringe and injected into the NMR tube just before starting the measurement. The molar ratio between hydroxide and QA salt is ca. 28:1. After the injection, the tube was mixed and inserted into the NMR equipment. NMR measurements were carried out repeatedly with time intervals according to the rate of decomposition.

The actual base concentrations were measured in separate solution preparations using automatic titration. The solution was prepared in the same way, filtered through a $0.22 \mu \mathrm{m}$ Teflon filter, and titrated after addition of water with $1 \mathrm{M} \mathrm{HCl}$. Hydroxide concentrations were found to be $0.64 \mathrm{M}$.

For the experiments with known quantities of water per hydroxide anion, the DMSO- $d_{6}$ added to dissolve the QA was reduced by the volume of water needed for the reaction. The water was added to the reaction mixture and mixed before the addition of the QA. The number of molecules of water per hydroxide anion is defined here as $\lambda$. As an example, an NMR experiment with 4 water molecules per hydroxide $(\lambda=4)$ required addition of $36 \mu \mathrm{L}(2 \mathrm{mmol})$ of water. In that case, the QA $(0.035 \mathrm{mmol})$ was dissolved in $64 \mu \mathrm{L}$ of DMSO- $d_{6}$. The first solution $(400 \mu \mathrm{L})$ was added to the NMR tube, and the tube was sealed. Milli-Q water $(36 \mu \mathrm{L})$ was then injected into the NMR tube. After the tube was mixed, the QA solution was injected into the tube and mixed again. This was the starting point of the experiment $(t$ $=0$ ), and the tube was inserted into the instrument for measurement. NMR measurements were carried out in a Bruker Avance 300 operating at $300 \mathrm{MHz}$ for ${ }^{1} \mathrm{H}$. For quantification of the reaction, integration of the aromatic part of the QA and its degradation product were compared to the mesitylene aromatic singlet peak.

Computational Methods. DFT calculations were performed with the G09 program (revision D.01). ${ }^{32}$ Geometries of all models were optimized and verified as minima, ensuring all positive frequencies. The transition states were optimized and verified to have one negative frequency. The $x y z$ coordinates of all transition state structures are provided in the Supporting Information (SI). The B3LYP functional ${ }^{33}$ with the $6-311++g(2 d, p)$ basis set ${ }^{34}$ was used for all calculations. The optimized structures (both minima and transition states) were further recomputed as single point energy calculations with the polarizable continuum solvent model ${ }^{35}$ using DMSO as a solvent.

The basis set superposition error (BSSE) was evaluated using the counterpoise correction method ${ }^{36}$ as single point energy calculation at the B3LYP $/ 6-311++g(2 \mathrm{~d}, \mathrm{p})$ optimized transition state structures. For the BSSE evaluation, the transition state molecules were partitioned using two schemes: (a) The molecule was divided into two fragments, the QA and the nucleophile cluster, $\mathrm{OH}^{-}\left(\mathrm{H}_{2} \mathrm{O}\right)_{\lambda}$. This results in BSSE corrections range from 1.63 to $2.83 \mathrm{kcal} \mathrm{mol}^{-1}$ (see Table S2 in the SI for individual values). (b) The molecule was divided into $1+\lambda$ fragments, i.e., the $S_{\mathrm{N}} 2$ transition state complex and each additional water molecule, $\lambda=1-4$. The BSSE correction was found to be ranging from 0.98 to $3.30 \mathrm{kcal} \mathrm{mol}^{-1}$ at the transition state structure as a function of number of water molecules (individual values can be found in the SI). This energetic contribution due to the localized basis does not change the computed trend in nucleophilic substitution activation energies as a function of number of water molecules since the variation in the activation energies exceeds the BSSE contribution of maximum $\sim 3.30 \mathrm{kcal} \mathrm{mol}^{-1}$.

The nucleophilicity index, NI, was computed for $\mathrm{OH}^{-}\left(\mathrm{H}_{2} \mathrm{O}\right)_{\lambda}$ clusters according to the method introduced by Perez and coworkers, ${ }^{37}$ relying on the difference of the HOMO orbital energies of a nucleophile and that of a reference molecule. The optimized gas-phase geometries of $\mathrm{OH}^{-}\left(\mathrm{H}_{2} \mathrm{O}\right)_{\lambda}, \lambda=3,4$, are in agreement with previous $a b$ initio molecular dynamics simulations of $\mathrm{OH}^{-}$in water. ${ }^{38}$

\section{RESULTS AND DISCUSSION}

As a starting point, we tested the well-studied TMBA QA salt, using 4 equiv of water per hydroxide anion $(\lambda=4)$. This starting point should resemble studies that used $10 \mathrm{M} \mathrm{KOH}$ in water, in which ca. 5 water molecules per hydroxide are present. Using our proposed technique, the stability test of the TMBA salt was continuously performed for a period of more than 700 $\mathrm{h}$ at room temperature. Figure 1 shows the aromatic area of the NMRs obtained during the stability tests of TMBA salt in the presence of 28 equiv of $\mathrm{OH}^{-}$and 4 water molecules per $\mathrm{OH}^{-}$.

NMR measurements show that TMBA aromatic signals (7.4-7.65 ppm) are still present after 31 days in these reaction conditions, indicating that when 4 molecules of water per hydroxide are present, TMBA is fairly stable. These results resemble those found in the literature. Marino and Kreuer, for instance, found that the activation enthalpy for the overall decomposition process of TMBA in $10 \mathrm{M} \mathrm{NaOH}$ aqueous solution is as high as $120 \mathrm{~kJ} \mathrm{~mol}^{-1}$, and that at $80{ }^{\circ} \mathrm{C}$ (relevant temperature for fuel cell operation) the half-life of TMBA is above $2000 \mathrm{~h}^{10}$ Yet, when a TMBA analogue is tested directly in an AEMFC, the stability is lost quite fast. ${ }^{39-41}$

In all ex situ stability tests reported in the literature, even when high alkali concentrations are used, water is always present in the alkaline solutions where QA stability was measured. As previously described, the nucleophilicity (and therefore QA stability) of $\mathrm{OH}^{-}$depends also on the degree of 


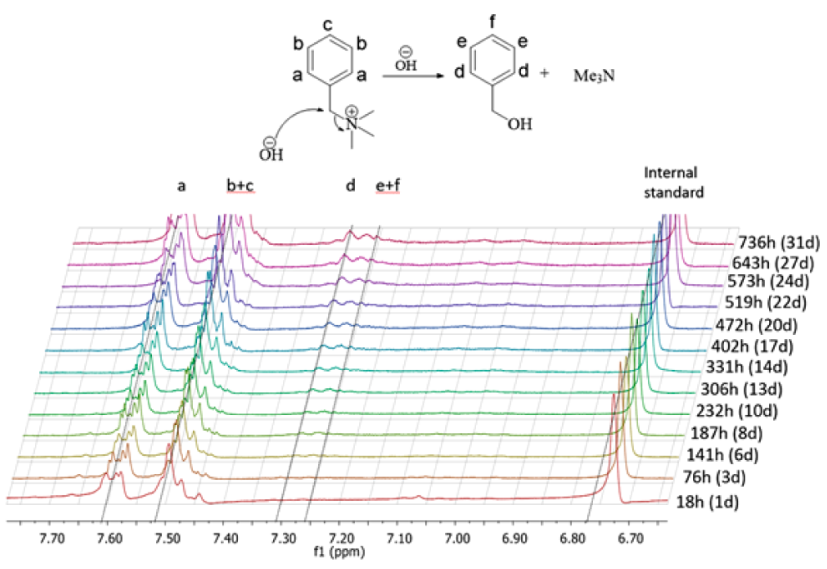

Figure 1. Aromatic section of NMR as a function of time during testing of the TMBA salt with $0.64 \mathrm{M} \mathrm{OH}^{-}$and 4 molecules of water per $\mathrm{OH}^{-}(\lambda=4)$ in DMSO- $d_{6}$ at room temperature. Mesitylene is used as internal standard.

solvation, ${ }^{10}$ and for that reason several authors have been raising $\mathrm{NaOH} / \mathrm{KOH}$ concentrations to up to $10 \mathrm{M}^{10,42,43}$ (5 water molecules per $\mathrm{OH}^{-}$, i.e., $\lambda=5$ ). At this level of hydration, there are still enough water molecules to fill the first solvation sphere of the $\mathrm{OH}^{-}$and affect its nucleophilic character. In addition, when the aqueous alkali solution is too concentrated, viscosity effects may come into play and interfere with the stability measurements (e.g., diffusion of $\mathrm{OH}^{-}$nucleophiles toward the cationic groups is retarded). Both factors affect the nucleophilic character of the $\mathrm{OH}^{-}$anion leading to false positive stability results showing QA salts to be more alkali stable than they really are.

In an operating AEMFC, the water depletion in the cathode is severe, reducing the water concentration to very low levels. At ultralow hydration levels (corresponding to high fuel cell current densities), the hydroxide environment ("solvation") is not defined by the water, but the water molecules present still coordinate the hydroxide in a process called microsolvation. The microsolvation of hydroxide has been intensively studied by theory ${ }^{44-46}$ and gas-phase experiments, ${ }^{47,48}$ and these studies agree that tiny amounts of water can severely impede the kinetics of nucleophiles. Using our proposed technique we can keep $\mathrm{OH}^{-}$concentration relatively low $(0.64 \mathrm{M})$, and separately control the water $/ \mathrm{OH}^{-}$ratio in the solution. Figure 2 shows the same experiment under otherwise similar conditions, but the TMBA/KOH solution is now water-free (ca. $63 \mathrm{ppm}$ of water, i.e., water $/ \mathrm{OH}^{-}$ratio $<0.1$ ).

In contrast to the case of 4 water molecules per $\mathrm{OH}^{-}$, when no water is present, the TMBA degrades quite rapidly. As observed in Figure 2, TMBA signals at 7.4-7.65 ppm disappear after a few days, while signals at 7.2-7.35 ppm, which correspond to the aromatic hydrogens of benzyl alcohol, emerge. The contrast between results shown in Figures 1 and 2 clearly indicates the effect water has on the nucleophilicity of hydroxide; TMBA degrades significantly faster as a result of the nucleophilic attack of the $\mathrm{OH}^{-}$in the absence of water. The degradation reaction follows the expected $\mathrm{S}_{\mathrm{N}} 2$ mechanism, ${ }^{1,10,17,49-51}$ which is shown in Figure 2.

To further confirm the effect water molecules have on the nucleophilicity of hydroxide, additional alkaline stability tests of TMBA were carried out using 1, 2, and 3 water molecules per $\mathrm{OH}^{-}$and followed by NMR spectroscopy. Figure 3 summarizes

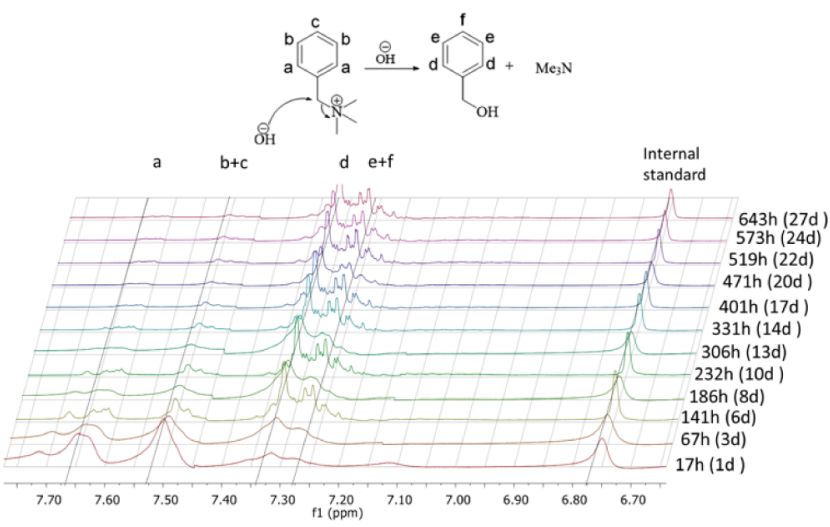

Figure 2. Aromatic section of NMR as a function of time during testing of the TMBA salt with $0.64 \mathrm{M} \mathrm{OH}^{-}$in water-free DMSO- $d_{6}(\lambda$ $=0$ ), at room temperature. Mesitylene is used as internal standard.

the TMBA concentration as a function of time for stability tests carried out with different water molecules per $\mathrm{OH}^{-}$.

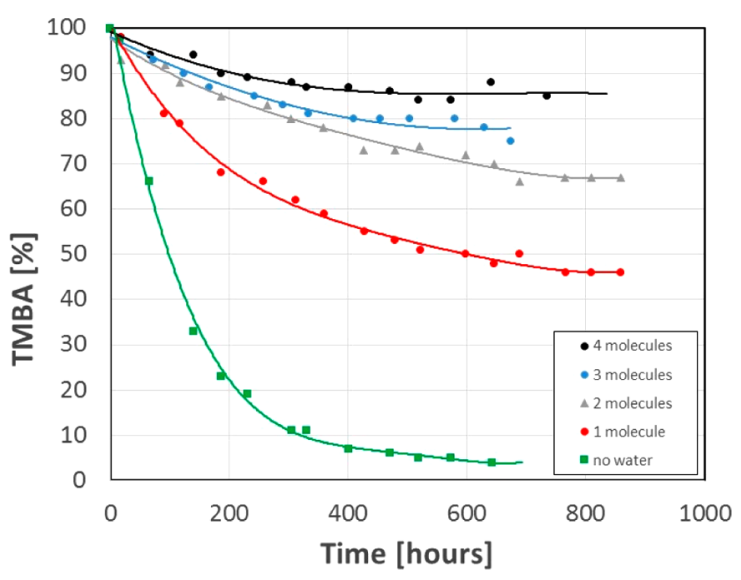

Figure 3. TMBA concentration as a function of time in $0.64 \mathrm{M} \mathrm{OH}^{-}$ DMSO- $d_{6}$ solutions for $\lambda=0,1,2,3$, and 4 . All tests were done at room temperature.

As can be clearly seen from Figure 3, the decomposition rate of TMBA increases as water content is reduced. While TMBA is quite stable with 4 water molecules per $\mathrm{OH}^{-}(\lambda=4)$, showing $15 \%$ degradation after $700 \mathrm{~h}$ of test, in the absence of water $(\lambda=0)$, TMBA shows a $50 \%$ degradation rate already after $100 \mathrm{~h}$ of test, and full decomposition after only $600 \mathrm{~h}$. While the effect of solvation in nucleophilic reactions is wellknown, it should be remarked that the microsolvation (ultralow hydration levels) of hydroxide in a similar solvent environment has a massive effect on the measured reaction kinetics. This clear difference strongly points out, for the first time, the critical importance of water in the stability properties of ionomeric materials for AEMFCs.

Our new ex situ test better simulates the environment of an anionic exchange membrane in the cathode electrode in an AEMFC when it is in operation. As previously mentioned, when current densities are applied in an AEMFC device, the water is consumed due to the oxygen reduction reaction:

$$
1 / 2 \mathrm{O}_{2}+\mathrm{H}_{2} \mathrm{O}+2 \mathrm{e}^{-} \rightarrow 2 \mathrm{OH}^{-}
$$

As we increase the operating current density of the fuel cell, the water is consumed faster, and the cathode electrode becomes drier. Fewer and fewer water molecules are available 
to solvate the increased amount of formed $\mathrm{OH}^{-}$, and then, the nucleophilic attack on the functional groups of the ionic polymer is accelerated. At a certain current density maximum threshold, the $\mathrm{OH}^{-}$is not solvated by water molecules at all (microsolvation stage), and therefore, it becomes so aggressive that a stable molecule such as TMBA can be degraded at room temperature in a matter of hours, as shown in Figure 3. These results indicate that the water molecules, which are strongly bound to the hydroxide, reduce its nucleophilicity, "shielding" it from attacking the QA, as schematically illustrated in Scheme 1.

Scheme 1. Schematic Diagram of Nucleophilic Attack onto TMBA with and without Water ${ }^{a}$

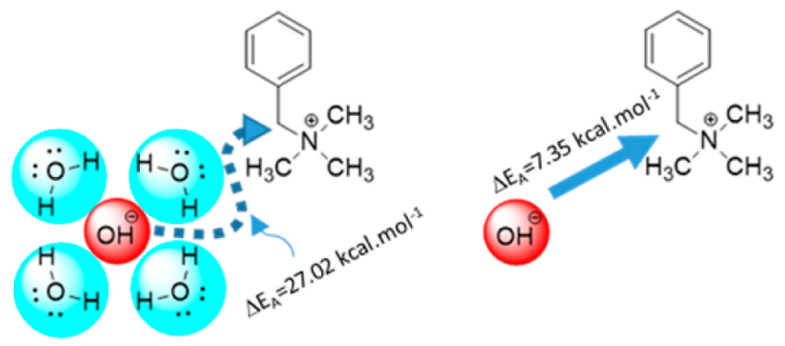

${ }^{a}$ Water solvating molecules show "shield" effect on the $\mathrm{OH}^{-}$ nucleophilic attack onto the QA. Activation energy calculated by DFT.

To further understand this shielding effect of water solvating the $\mathrm{OH}^{-}$on its nucleophilicity in the presence of QA cations, a series of DFT calculations were performed. Nucleophilic substitution reaction energies, $\Delta E_{\mathrm{R}}$, and activation energies, $\Delta E_{\mathrm{A}}$, at the benzylic carbon atom, were computed according to the model $S_{N} 2$ reaction profile depicted in Figure 4; results are summarized in Table 1 .

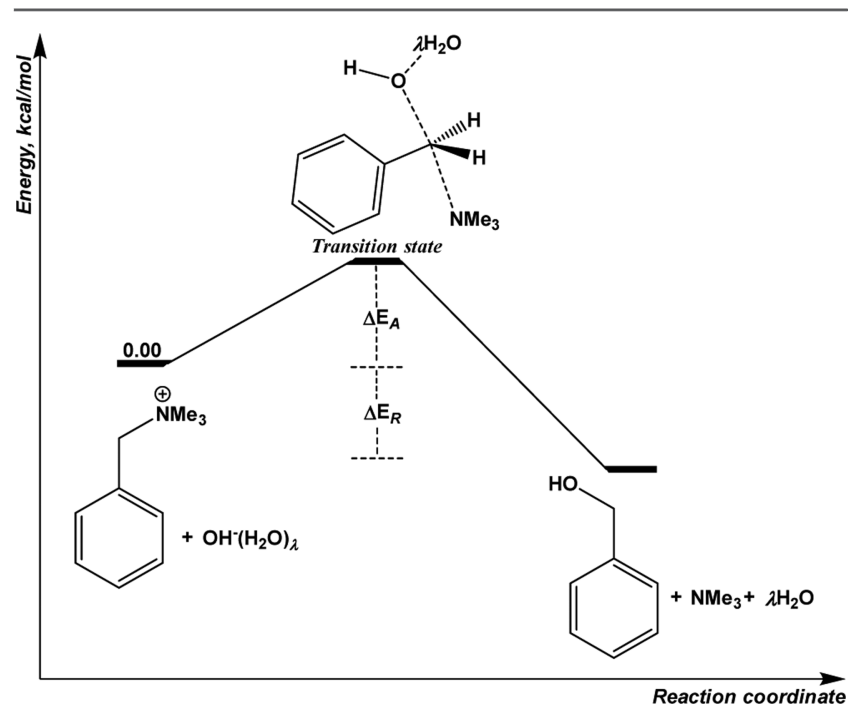

Figure 4. Schematic representation of a decomposition path of TMBA by nucleophilic substitution at the benzylic carbon.

Our DFT calculations indicate that, for the bare nucleophile, $\mathrm{OH}^{-}(\lambda=0)$, the overall reaction (see Figure 1 ) is exothermic, with the benzyl alcohol and trimethylamine products computed to be $29.75 \mathrm{kcal} \mathrm{mol}^{-1}$ below the reacting TMBA and the hydroxide anion, $\mathrm{OH}^{-}$. This is in agreement with the previously computed reaction energy of $-29.5 \mathrm{kcal} \mathrm{mol}^{-1} .52$ As the number of the solvating water molecules increases, the reaction
Table 1. Values for Computed Activation Energy, $\Delta E_{\mathrm{A}}$ Reaction Energy, $\Delta E_{\mathrm{R}}$ and Nucleophilicity Index, $\mathrm{NI}{ }^{37}$ at the B3LYP/6-311++g(2d,p)//DMSO ${ }^{a}$ Level of Theory

\begin{tabular}{|c|c|c|c|}
\hline $\begin{array}{l}\lambda \text {, number of water } \\
\text { molecules per } \mathrm{OH}^{-}\end{array}$ & $\begin{array}{c}\Delta E_{\mathrm{A}} \\
\mathrm{kcal} \mathrm{\textrm {mol } ^ { - 1 }}\end{array}$ & $\begin{array}{c}\Delta E_{\mathrm{R}} \\
\mathrm{kcal} \mathrm{mol}^{-1}\end{array}$ & NI, eV \\
\hline 0 & 7.35 & -29.75 & 3.64 \\
\hline 1 & 13.78 & -17.06 & 2.95 \\
\hline 2 & 18.43 & -6.23 & 2.63 \\
\hline 3 & 22.63 & 3.61 & 2.25 \\
\hline 4 & 27.02 & 8.81 & 2.06 \\
\hline
\end{tabular}

${ }^{a}$ Single point calculations using implicit model of DMSO as a solvent, at the B3LYP/6-311++g(2d,p) optimized geometries.

becomes less exothermic for $\lambda=1,2$ and eventually endothermic for $\lambda=3,4$, reaching $8.81 \mathrm{kcal} \mathrm{mol}^{-1}$ for $\lambda=4$ (see Table 1). This trend probably results from the stabilizing effect of each water molecule on the reacting $\mathrm{OH}^{-}\left(\mathrm{H}_{2} \mathrm{O}\right)_{\lambda}$ nucleophile on one hand, and destabilization of the separate water molecules as part of the products on the other.

As seen in Table 1, the computed activation energies for the reaction with $\lambda=0,1,2,3$, and 4 show a gradual increase in the activation barrier from $7.35 \mathrm{kcal} \mathrm{mol}^{-1}$ for bare $\mathrm{OH}^{-}$, i.e., $\lambda=0$, up to $27.02 \mathrm{kcal} \mathrm{mol}^{-1}$ for $\lambda=4$, i.e., 4 water molecules coordinated to the $\mathrm{OH}^{-}$(see SI for individual structures). This observed trend of increasing activation energies as the number of water molecules, $\lambda$, increases can be rationalized in terms of a decrease in nucleophilicity of $\mathrm{OH}^{-}\left(\mathrm{H}_{2} \mathrm{O}\right)_{\lambda}$. This was further corroborated by computing the nucleophilicity index, NI, see Table $1 .{ }^{37}$ The computed NI for $\lambda=0$ is 3.64 , decreasing gradually to $2.95,2.63,2.25$, and 2.06 for $\lambda=1,2,3$, and 4 , respectively. These values suggest that the bare $\mathrm{OH}^{-}$is a strong nucleophile, the $\mathrm{OH}^{-}\left(\mathrm{H}_{2} \mathrm{O}\right)_{\lambda}$ species with $\lambda=1-3$ are moderate, and $\mathrm{OH}^{-}\left(\mathrm{H}_{2} \mathrm{O}\right)_{4}$ is a marginally weak nucleophile. ${ }^{37}$ For the studied concentration of water $(\lambda=0-4)$, a linear correlation was found between the NI and the $S_{N} 2$ reaction barriers (see SI), indicating that the decrease in nucleophilicity index of $\mathrm{OH}^{-}\left(\mathrm{H}_{2} \mathrm{O}\right)_{\lambda}$ is accompanied by an increase in nucleophilic substitution reaction barriers.

Finally, in order to determine whether our new ex situ stability can also predict stability of a QA based functional group in a simulated fuel cell environment where the QA decomposes by a different degradation mechanism, we decided to also test TEBA. While similar in structure to TMBA, TEBA has three $N$-ethyl groups in which acidic $\beta$ hydrogens can be rapidly abstracted by the hydroxide. In the case of TEBA, a Hoffman degradation mechanism overrides the benzylic $S_{N} 2$ mechanism, following the reaction shown in Figure 5. Figure 5 also shows the NMR results of stability tests for $\lambda=1$, and Figure 6 summarizes the stability tests of TEBA in $0.64 \mathrm{M} \mathrm{OH}^{-}$ in DMSO- $d_{6}$ and different water $/ \mathrm{OH}^{-}$ratios $(\lambda=0,1,2,3$, and 4).

Figures 5 and 6 indicate that the decomposition of TEBA is much faster than the degradation of TMBA, as expected. ${ }^{53}$ In the Hoffman degradation mechanism, hydroxide acts as a base, absorbing the $\beta$ hydrogen through an E2 mechanism. This reaction can be followed by the appearance of $N, N$ diethylbenzylamine peaks in the NMR. This is consistent with previous reports in the literature. ${ }^{1,6}$ Importantly, water is produced by this reaction, yet even at $100 \%$ conversion, the amount of water produced does not significantly affect the water $/ \mathrm{OH}^{-}$ratio $\lambda$. 


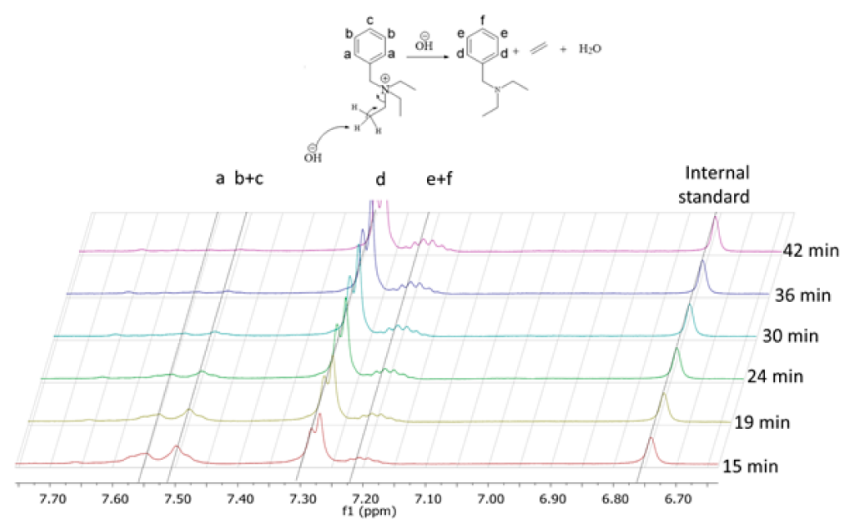

Figure 5. Change in NMR as a function of time of TEBA solution with $0.64 \mathrm{M} \mathrm{OH}^{-}$and 1 molecule of water per $\mathrm{OH}^{-}(\lambda=1)$, at room temperature. Mesitylene is used as internal standard.

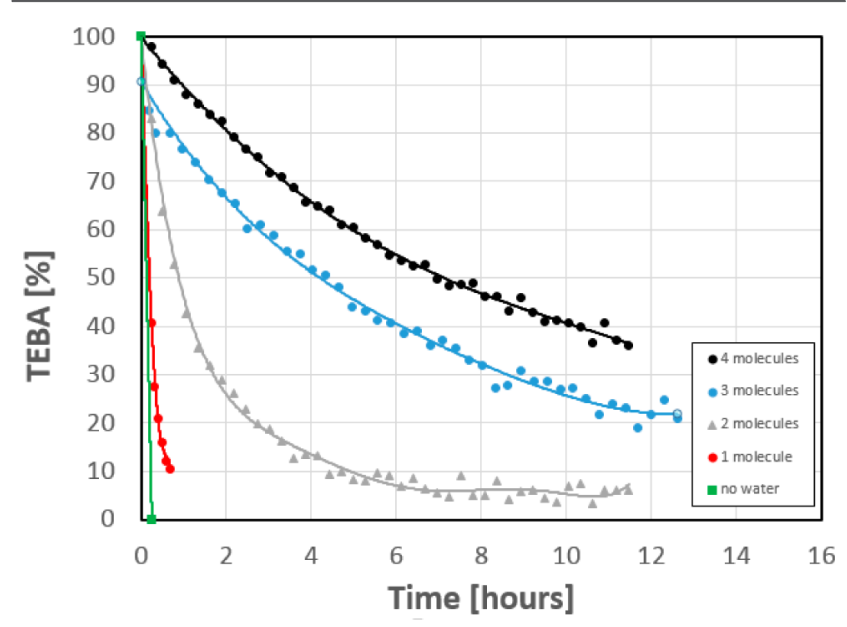

Figure 6. TEBA concentration as a function of time in $0.64 \mathrm{M} \mathrm{OH}^{-}$ DMSO- $d_{6}$ solutions for $\lambda=0,1,2,3$, and 4 . All tests were done at room temperature.

Figure 6 shows that the same trend obtained with TMBA is also observed for the decomposition of TEBA, i.e., the water/ $\mathrm{OH}^{-}$ratio significantly impacts the reaction rate. However, TEBA completely decomposes in a few hours, which is significantly faster than the decomposition observed for TMBA. For cases of no water and 1 water molecule per $\mathrm{OH}^{-}(\lambda=0$ and $\lambda=1$, respectively), the decomposition rate is so fast that it was very difficult to measure due to the short time available from the beginning of the test until full decomposition.

Although TEBA decomposition has been previously reported to be around 6 times faster than the decomposition rate of TMBA, ${ }^{10}$ in practice this ratio also depends on the water content. For instance, for 1 water molecule per hydroxide, $\lambda=$ 1 , we can see that $50 \%$ decomposition is reached in $600 \mathrm{~h}$ and in $\sim 0.2 \mathrm{~h}$, for TMBA and TEBA, respectively. This indicates that, in AEMFCs operated at high current density, conditions in which very low content of water exist in the cathode side, TEBA is expected to decompose ca. 3000 times faster than TMBA.

The clear differences demonstrated between our ex situ stability tests and currently available used techniques based on aqueous systems strongly points out, for the first time, the critical importance of water in the stability properties of ionomeric materials for AEMFCs. The newly proposed methodology better simulates the environment of a fuel cell, taking into consideration the critical effect of low water content.

\section{CONCLUSIONS}

We have successfully developed a practical novel protocol for $e x$ situ measurements of true chemical stability of cationic functional groups to be used as anion exchange membranes and anion exchange ionomers for AEMFCs. The developed protocol is capable of simultaneously setting the polymer and hydroxide concentrations, independently of the water content, successfully simulating the in situ environment of an AEMFC in operation.

Using this developed protocol we found that while some QA cations are very stable under the currently available stability experimental tests, when ultralow water content is present in the medium, as is the real case in the cathode of an AEMFC in operation, the QAs are rapidly degraded, as typically observed in real fuel cell tests. While previous studies have shown that water molecules coordinating the $\mathrm{OH}^{-}$anions by solvation affect the kinetics of QA stability, ${ }^{10}$ our studies show that this effect is significantly stronger at ultralow hydration numbers. Although the effect of water on the stability of isolated QA model molecules in solution is different from that for solid state AEMs, these results strongly indicate that currently used aqueous alkali ex situ tests to measure AEM stability may lead to false positive stability results where anion conducting polymers may appear more alkali stable than they really are in an AEMFC environment during operation, in which the hydration numbers are very low.

We strongly recommend the adoption of this newly developed technique to measure the true stability of anion conducting polymers to be used for AEMFCs. We believe that this new ex situ protocol will rapidly lead to development and selection of best stable polymers for durable and robust AEMFCs.

\section{ASSOCIATED CONTENT}

\section{Supporting Information}

The Supporting Information is available free of charge on the ACS Publications website at DOI: 10.1021/acs.chemmater.7b00958.

Pictures of experimental setup, kinetic graphs, NMR data, and computational data (PDF)

\section{AUTHOR INFORMATION}

\section{Corresponding Authors}

*E-mail: dario@technion.ac.il.

*E-mail: charles@technion.ac.il.

ORCID

Charles E. Diesendruck: 0000-0001-5576-1366

Notes

The authors declare no competing financial interest.

\section{ACKNOWLEDGMENTS}

This work was partially funded by the Grand Technion Energy Program (GTEP); by the European Union's Horizon 2020 research and innovation programme under grant agreement 721065; by the Ministry of Science, Technology \& Space of Israel through the M.era-NET Transnational Call 2015, NEXTGAME project grant 3-12948; by the Ministry of National Infrastructure, Energy and Water Resources of Israel 
(grant 216-11-048); and by the 2nd Israel National Research Center for Electrochemical Propulsion (INREP2-ISF). Additionally we thank Dr. Uri Ash for his help with solution preparation for NMR testing.

\section{ABBREVIATIONS}

AEI, anion exchange ionomer; AEMFC, anion exchange membrane fuel cell; IEC, ion exchange capacity; NMR, nuclear magnetic resonance; QA, quaternary ammonium; TEBA, triethylbenzylammonium; TMBA, trimethylbenzylammonium

\section{REFERENCES}

(1) Varcoe, J. R.; Atanassov, P.; Dekel, D. R.; Herring, A. M.; Hickner, M. A.; Kohl, P. A.; Kucernak, A. R.; Mustain, W. E.; Nijmeijer, K.; Scott, K.; Xu, T.; Zhuang, L. Anion-Exchange Membranes in Electrochemical Energy Systems. Energy Environ. Sci. 2014, 7, 3135-3191.

(2) Cheng, J.; He, G.; Zhang, F. A Mini-Review on Anion Exchange Membranes for Fuel Cell Applications: Stability Issue and Addressing Strategies. Int. J. Hydrogen Energy 2015, 40 (23), 7348-7360.

(3) Amel, A.; Smedley, S. B.; Dekel, D. R.; Hickner, M. A.; Ein-Eli, Y. Characterization and Chemical Stability of Anion Exchange Membranes Cross-Linked with Polar Electron-Donating Linkers. J. Electrochem. Soc. 2015, 162 (9), F1047-F1055.

(4) Miyake, J.; Fukasawa, K.; Watanabe, M.; Miyatake, K. Effect of Ammonium Groups on the Properties and Alkaline Stability of Poly(arylene Ether)-Based Anion Exchange Membranes. J. Polym. Sci., Part A: Polym. Chem. 2014, 52 (3), 383-389.

(5) Lee, J. Y.; Lim, D. H.; Chae, J. E.; Choi, J.; Kim, B. H.; Lee, S. Y.; Yoon, C. W.; Nam, S. Y.; Jang, J. H.; Henkensmeier, D.; Yoo, S. J.; Kim, J. Y.; Kim, H. J.; Ham, H. C. Base Tolerant Polybenzimidazolium Hydroxide Membranes for Solid Alkaline-Exchange Membrane Fuel Cells. J. Membr. Sci. 2016, 514, 398-406.

(6) Mohanty, A. D.; Bae, C. Mechanistic Analysis of Ammonium Cation Stability for Alkaline Exchange Membrane Fuel Cells. J. Mater. Chem. A 2014, 2 (41), 17314-17320.

(7) Nuñez, S. A.; Capparelli, C.; Hickner, M. A. N -Alkyl Interstitial Spacers and Terminal Pendants Influence the Alkaline Stability of Tetraalkylammonium Cations for Anion Exchange Membrane Fuel Cells. Chem. Mater. 2016, 28 (8), 2589-2598.

(8) Nuñez, S. A.; Hickner, M. A. Quantitative 1 H NMR Analysis of Chemical Stabilities in Anion-Exchange Membranes. ACS Macro Lett. 2013, 2 (1), 49-52.

(9) Merle, G.; Wessling, M.; Nijmeijer, K. Anion Exchange Membranes for Alkaline Fuel Cells: A Review. J. Membr. Sci. 2011, $377(1-2), 1-35$.

(10) Marino, M. G.; Kreuer, K. D. Alkaline Stability of Quaternary Ammonium Cations for Alkaline Fuel Cell Membranes and Ionic Liquids. ChemSusChem 2015, 8 (3), 513-523.

(11) Edson, J. B.; Macomber, C. S.; Pivovar, B. S.; Boncella, J. M. Hydroxide Based Decomposition Pathways of Alkyltrimethylammonium Cations. J. Membr. Sci. 2012, 399-400, 49-59.

(12) Ponce-Gonzalez, J.; Whelligan, D. K.; Wang, L.; Bance-Soualhi, R.; Wang, Y.; Peng, Y.; Peng, H.; Apperley, D. C.; Sarode, H. N.; Pandey, T. P.; Divekar, A. G.; Seifert, S.; Herring, A.; Zhuang, L.; Varcoe, J. R. High Performance Aliphatic-Heterocyclic BenzylQuaternary Ammonium Radiation-Grafted Anion-Exchange Membranes. Energy Environ. Sci. 2016, 9, 3724-3735.

(13) Hibbs, M. R. Alkaline Stability of Poly(phenylene)-Based Anion Exchange Membranes with Various Cations. J. Polym. Sci., Part B: Polym. Phys. 2013, 51 (24), 1736-1742.

(14) Komkova, E. N.; Stamatialis, D. F.; Strathmann, H.; Wessling, M. Anion-Exchange Membranes Containing Diamines: Preparation and Stability in Alkaline Solution. J. Membr. Sci. 2004, 244 (1-2), 2534.

(15) Pandey, T. P.; Sarode, H. N.; Yang, Y.; Yang, Y.; Vezzù, K.; Noto, V.; Seifert, S.; Knauss, D. M.; Liberatore, M. W.; Herring, A. M. A Highly Hydroxide Conductive, Chemically Stable Anion Exchange
Membrane, Poly(2,6 Dimethyl 1,4 Phenylene Oxide)- B -Poly(vinyl Benzyl Trimethyl Ammonium), for Electrochemical Applications. J. Electrochem. Soc. 2016, 163 (7), H513-H520.

(16) Yu Xu, P.; Zhou, K.; Lu Han, G.; Gen Zhang, Q.; Mei Zhu, A.; Lin Liu, Q. Fluorene-Containing Poly(arylene Ether Sulfone)s as Anion Exchange Membranes for Alkaline Fuel Cells. J. Membr. Sci. 2014, 457, 29-38.

(17) Hugar, K. M.; Kostalik, H. A.; Coates, G. W. Imidazolium Cations with Exceptional Alkaline Stability: A Systematic Study of Structure-Stability Relationships. J. Am. Chem. Soc. 2015, 137 (27), 8730-8737.

(18) Xu, P. Y.; Zhou, K.; Han, G. L.; Zhang, Q. G.; Zhu, A. M.; Liu, Q. L. Effect of Fluorene Groups on the Properties of Multiblock Poly(arylene Ether Sulfone)s-Based Anion-Exchange Membranes. ACS Appl. Mater. Interfaces 2014, 6 (9), 6776-6785.

(19) Lin, X.; Gong, M.; Liu, Y.; Wu, L.; Li, Y.; Liang, X.; Li, Q.; Xu, T. A Convenient, Efficient and Green Route for Preparing Anion Exchange Membranes for Potential Application in Alkaline Fuel Cells. J. Membr. Sci. 2013, 425-426, 190-199.

(20) Arges, C. G.; Wang, L.; Jung, M. -s.; Ramani, V. Mechanically Stable Poly(arylene Ether) Anion Exchange Membranes Prepared from Commercially Available Polymers for Alkaline Electrochemical Devices. J. Electrochem. Soc. 2015, 162 (7), F686-F693.

(21) Li, Q.; Liu, L.; Miao, Q.; Jin, B.; Bai, R. A Novel poly(2,6Dimethyl-1,4-Phenylene Oxide) with Trifunctional Ammonium Moieties for Alkaline Anion Exchange Membranes. Chem. Commun. (Cambridge, U. K.) 2014, 50 (21), 2791-2793.

(22) Dekel, D. Alkaline Membrane Fuel Cells. In Encyclopedia of Applied Electrochemistry; Kreysa, G., Ota, K., Savinell, R. F., Eds.; Springer: New York, 2014; pp 26-33.

(23) Staszak-Jirkovský, J.; Subbaraman, R.; Strmcnik, D.; Harrison, K. L.; Diesendruck, C. E.; Assary, R.; Frank, O.; Kobr, L.; Wiberg, G. K H.; Genorio, B.; Connell, J. G.; Lopes, P. P.; Stamenkovic, V. R.; Curtiss, L.; Moore, J. S.; Zavadil, K. R.; Markovic, N. M. Water as a Promoter and Catalyst for Dioxygen Electrochemistry in Aqueous and Organic Media. ACS Catal. 2015, 5 (11), 6600-6607.

(24) Zhang, Q.; Li, S.; Zhang, S. A Novel Guanidinium Grafted Poly(aryl Ether Sulfone) for High-Performance Hydroxide Exchange Membranes. Chem. Commun. 2010, 46 (40), 7495-7497.

(25) Fang, J.; Yang, Y.; Lu, X.; Ye, M.; Li, W.; Zhang, Y. CrossLinked, ETFE-Derived and Radiation Grafted Membranes for Anion Exchange Membrane Fuel Cell Applications. Int. J. Hydrogen Energy 2012, 37 (1), 594-602.

(26) Hirsch, M.; Dhara, S.; Diesendruck, C. E. N-Arylation of Tertiary Amines under Mild Conditions. Org. Lett. 2016, 18 (5), 980983.

(27) Pham, T. H.; Jannasch, P. Aromatic Polymers Incorporating BisN-Spirocyclic Quaternary Ammonium Moieties for Anion-Exchange Membranes. ACS Macro Lett. 2015, 4 (12), 1370-1375.

(28) Li, Z.; Wang, W.; Chen, Y.; Xiong, C.; He, G.; Cao, Y.; Wu, H.; Guiver, M. D.; Jiang, Z. Constructing Efficient Ion Nanochannels in Alkaline Anion Exchange Membranes by the in Situ Assembly of a Poly(ionic Liquid) in Metal-Organic Frameworks. J. Mater. Chem. A 2016, 4 (6), 2340-2348.

(29) Wright, A. G.; Holdcroft, S. Hydroxide-Stable Ionenes. ACS Macro Lett. 2014, 3 (5), 444-447.

(30) Zhu, L.; Pan, J.; Wang, Y.; Han, J.; Zhuang, L.; Hickner, M. A. Multication Side Chain Anion Exchange Membranes. Macromolecules 2016, 49 (3), 815-824.

(31) Dang, H.-S.; Jannasch, P. Exploring Different Cationic Alkyl Side Chain Designs for Enhanced Alkaline Stability and Hydroxide Ion Conductivity of Anion-Exchange Membranes. Macromolecules 2015, 48 (16), 5742-5751.

(32) Frisch, M.; Trucks, G.; Schlegel, H.; Scuseria, G.; Robb, M.; Cheeseman, J.; Scalmani, G.; Barone, V.; Mennucci, B.; Petersson, G.; Nakatsuji, H.; Caricato, M.; Li, X.; Hratchian, H.; Izmaylov, A.; Bloino, J.; Zheng, G.; Sonnenberg, J.; Hada, M.; Ehara, M.; Toyota, K.; Fukuda, R.; Hasegawa, J.; Ishida, M.; Nakajima, T.; Honda, Y.; Kitao, O.; Nakai, H.; Vreven, T.; Montgomery, J.; Peralta, J.; Ogliaro, F.; 
Bearpark, M.; Heyd, J.; Brothers, E.; Kudin, K.; Staroverov, V.; Kobayashi, R.; Normand, J.; Raghavachari, K.; Rendell, A.; Burant, J.; Iyengar, S.; Tomasi, J.; Cossi, M.; Rega, N.; Millam, J.; Klene, M.; Knox, J.; Cross, J.; Bakken, V.; Adamo, C.; Jaramillo, J.; Gomperts, R.; Stratmann, R.; Yazyev, O.; Austin, A.; Cammi, R.; Pomelli, C.; Ochterski, J.; Martin, R.; Morokuma, K.; Zakrzewski, V.; Voth, G.; Salvador, P.; Dannenberg, J.; Dapprich, S.; Daniels, A.; Farkas; Foresman, J.; Ortiz, J.; Cioslowski, J.; Fox, D. Gaussian 09, Revision. B.01; Gaussian, Inc.: Wallingford, CT, 2009.

(33) Becke, A. D. Density-Functional Exchange-Energy Approximation with Correct Asymptotic Behavior. Phys. Rev. A: At., Mol., Opt. Phys. 1988, 38 (6), 3098-3100.

(34) Ditchfield, R. Self-Consistent Molecular-Orbital Methods. IX. An Extended Gaussian-Type Basis for Molecular-Orbital Studies of Organic Molecules. J. Chem. Phys. 1971, 54 (2), 724-728.

(35) Miertuš, S.; Scrocco, E.; Tomasi, J. Electrostatic Interaction of a Solute with a Continuum. A Direct Utilizaion of AB Initio Molecular Potentials for the Prevision of Solvent Effects. Chem. Phys. 1981, 55 (1), 117-129.

(36) Simon, S.; Duran, M.; Dannenberg, J. J. How Does Basis Set Superposition Error Change the Potential Surfaces for HydrogenBonded Dimers? J. Chem. Phys. 1996, 105 (24), 11024-11031.

(37) Domingo, L.; Ríos-Gutiérrez, M.; Pérez, P. Applications of the Conceptual Density Functional Theory Indices to Organic Chemistry Reactivity. Molecules 2016, 21 (6), 748-769.

(38) Tuckerman, M.; Laasonen, K.; Sprik, M.; Parrinello, M. Ab Initio Molecular Dynamics Simulation of the Solvation and Transport of $\mathrm{H} 3 \mathrm{O}+$ and OH- Ions in Water. J. Phys. Chem. 1995, 99 (16), 57495752.

(39) Choe, Y. K.; Fujimoto, C.; Lee, K. S.; Dalton, L. T.; Ayers, K.; Henson, N. J.; Kim, Y. S. Alkaline Stability of Benzyl Trimethyl Ammonium Functionalized Polyaromatics: A Computational and Experimental Study. Chem. Mater. 2014, 26 (19), 5675-5682.

(40) Zhao, Y.; Yu, H.; Yang, D.; Li, J.; Shao, Z.; Yi, B. HighPerformance Alkaline Fuel Cells Using Crosslinked Composite Anion Exchange Membrane. J. Power Sources 2013, 221, 247-251.

(41) Li, N.; Leng, Y.; Hickner, M. A.; Wang, C. Y. Highly Stable, Anion Conductive, Comb-Shaped Copolymers for Alkaline Fuel Cells. J. Am. Chem. Soc. 2013, 135 (27), 10124-10133.

(42) Amel, A.; Zhu, L.; Hickner, M.; Ein-Eli, Y. Influence of Sulfone Linkage on the Stability of Aromatic Quaternary Ammonium Polymers for Alkaline Fuel Cells. J. Electrochem. Soc. 2014, 161 (5), F615-F621.

(43) Wang, J.; Wang, L. Preparation and Properties of OrganicInorganic Alkaline Hybrid Membranes for Direct Methanol Fuel Cell Application. Solid State Ionics 2014, 255, 96-103.

(44) Agmon, N.; Bakker, H. J.; Campen, R. K.; Henchman, R. H.; Pohl, P.; Roke, S.; Thamer, M.; Hassanali, A. Protons and Hydroxide Ions in Aqueous Systems. Chem. Rev. 2016, 116 (13), 7642-7672.

(45) Marx, D.; Chandra, A.; Tuckerman, M. E. Aqueous Basic Solutions: Hydroxide Solvation, Structural Diffusion, and Comparison to the Hydrated Proton. Chem. Rev. 2010, 110 (4), 2174-2216.

(46) Hub, J. S.; Wolf, M. G.; Caleman, C.; van Maaren, P. J.; Groenhof, G.; van der Spoel, D. Thermodynamics of Hydronium and Hydroxide Surface Solvation. Chem. Sci. 2014, 5, 1745-1749.

(47) Hierl, P. M.; Ahrens, A. F.; Henchman, M.; Viggiano, A. A.; Paulson, J. F.; Clary, D. C. Nucleophilic Displacement as a Function of Hydration Number and Temperature: Rate Constants and Product Distributions for OD-(D2O)0,1,2,3 + $\mathrm{CH} 3 \mathrm{Cl}$ at 200-500 K. J. Am. Chem. Soc. 1986, 108 (11), 3142-3143.

(48) Bohme, D. K.; Raksit, A. B. Gas-Phase Measurements of the Influence of Stepwise Solvation on the Kinetics of Nucleophilic Displacement Reactions with Chloromethane and Bromomethane at Room Temperature. J. Am. Chem. Soc. 1984, 106 (12), 3447-3452.

(49) Long, H.; Pivovar, B. Hydroxide Degradation Pathways for Imidazolium Cations: A DFT Study. J. Phys. Chem. C 2014, 118 (19), 9880-9888.

(50) Sturgeon, M. R.; Macomber, C. S.; Engtrakul, C.; Long, H.; Pivovar, B. S. Hydroxide Based Benzyltrimethylammonium Degrada- tion: Quantification of Rates and Degradation Technique Development. J. Electrochem. Soc. 2015, 162 (4), F366-F372.

(51) Zhang, W.; Van Duin, A. C. T. ReaxFF Reactive Molecular Dynamics Simulation of Functionalized Poly(phenylene Oxide) Anion Exchange Membrane. J. Phys. Chem. C 2015, 119 (49), 27727-27736.

(52) Chempath, S.; Boncella, J. M.; Pratt, L. R.; Henson, N.; Pivovar, B. S. Density Functional Theory Study of Degradation of Tetraalkylammonium Hydroxides. J. Phys. Chem. C 2010, 114 (27), 11977-11983.

(53) Sata, T.; Tsujimoto, M.; Yamaguchi, T.; Matsusaki, K. Change of Anion Exchange Membranes in an Aqueous Sodium Hydroxide Solution at High Temperature. J. Membr. Sci. 1996, 112 (2), 161-170. 